\title{
Utbildningar vid NASP, det svenska nationella centret för suicidforskning och prevention av psykisk ohälsa
}

\author{
Ved David Titelman
}

\section{Inledning}

I samband med att man i Sverige i början av 1990-talet skrev ett nationellt program för självmordsprevention, skapades ett center för självmordsforskning och prevention, idag kallat $\mathrm{N}$ ationellt centrum för suicidforskning och prevention av psykisk ohälsa (N A SP). C entret, som in rättades vid Stockholms läns landsting med placering vid Statens institut för psykosocial medicin (IPM), i nära organisatorisk anknytning till Institutionen för folkhälsovetenskap vid K arolinska Institutet, är idag också ett "collaborating centre" i W HO.

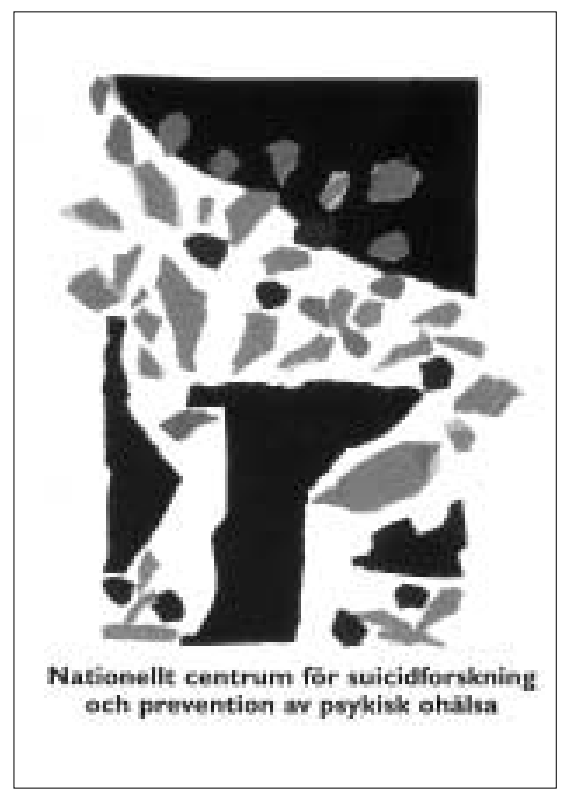

N A SP:s tre huvuduppgifter var från begynnelsen att sprida information om, bedriva och stödja forskning samt utbilda i befolknings- och individbaserad självmordsprevention.

U tbildningsverksamheten omfattar idag program som riktar sig till yrkesverksamma personer inom vuxen psykiatri, barn- och ungdomspsykiatri, primärvård, socialt arbete och skolan. Forskare inom psykiatri, psykologi och folkhälsovetenskap är en annan avnämargrupp. En tredje grupp är anhöriga till människor som tagit sitt liv, samtidigt som representanter för den svenska anhörigorganisationen, SPES (Suicidprevention och efterlevandes stöd) också anlitas som föreläsare i N A SP:s utbildningar.
G enomgående i N A SP:s olika utbildningar finns en betoning på att utbilda nyckel personer som sedan kan fungera som utbil dare eller handledare för att stärka de suicidpreventiva perspektiven på den egna arbetsplatsen. Denna utbildningsstrategi har evaluerats i en aktuell doktorsavhandling av Inga-Lill Ramberg (2003), "Promoting suicide prevention: A $n$ evaluation of a programme for training trainers in psychiatric clinical work". Ramberg dokumenterar en signifikant förändring av attityderna hos medarbetare i psykiatrin när det gäller att arbeta med självmordsnära patienter, efter att dessa medarbetare i början av 1990-talet gått i utbildningen " $\mathrm{H}$ andledarutbildning i suicidprevention" ( senare kallad "Suicidologi och suicidpreventivt arbete" och idag "Suicidprevention - teori och praktik").

En annan utgångspunkt för våra utbildningar är att självmord och själ vmordsnärhet kan förstås på ett fullödigt sätt endast genom en multidisciplinär ansats. M edarbetarskaran vid N A SP består därför av neurobiologiska forskare, epidemiologer, sociologer, kliniskt verksamma psykiatrer och psykologer av olika skolor (till exempel psykoanalytiker och kognitiva beteendeterapeuter), journalister, historiker och en filosof.

\section{Aktuella \\ utbildningsverksamheter}

Suicidprevention - teori och praktik

Denna utbildning är en 15-poängs (motsvarar 22.5 ECT S-poäng) fristående kurs vid Karolinska institutet, som är öppen för medarbetare i psykiatriska, barn- och ungdomspsykiatriska och sociala verksamheter. Förkunskapskraven är grundläggande högskoleutbildning (filosofie kandidatexamen eller 120 universitetspoäng, motsvarar 180 ECTSpoäng) och att den sökande i sitt arbete möter självmordsnära individer. Kursen, som i år ges för femte gången sedan 1993, lockar erfarna vuxen- och barn psykiatrer, psykologer, sjuksköterskor, socialarbetare och skolpersonal från hela Sverige. Cirka 25 personer deltar i varje utbildning.

U töver ett brett program av föreläsningar i suicidologi, presenteras föreläsningar om praktiska suicidpreventiva program riktade mot sårbara befolkningsgrupper, till exempel alkohol- och drogmissbrukare, psykiatriska patienter med personlighetsstörningar respektive psykoser, äldre, barn i familjer där någon tagit sitt liv. Suicidprevention bland ungdomar och unga vuxna är ett centralt tema i kursen.

Ett annat delmoment är att ge kursdeltagarna en teoretisk orientering och praktisk övning i att leda retrospektiva genomgångar eller "psykologiska autopsier" efter ett inträffat självmord eller självmordsförsök. De retrospektiva genomgångarnas dubbla funktion av förståel se-process ( när det gäller självmord och suicidalitet) och personlig bearbetning - det senare ligger nära "debriefing" - betonas.

I obligatoriska seminariegrupper, som är sammanhållna över hela kursen, ges studenterna tillfälle att diskutera såväl föreläsningsstoffet som kliniska erfarenheter av och personliga reaktioner på självmord och andra självmordshandlingar. U töver föreläsningar och seminarier är ett grundmoment i kursen att planera och genomföra ett forsknings- eller metodutvecklingsprojekt, som skall dokumenteras i en kort uppsats på 5 poäng ( 7.5 ECTS) utav kursens totalt 15 poäng (22.5 ECTS). H är är några exempel på uppsatsämnen:

- Lokal a epidemiologiska undersökningar.

- Rutiner för bemötande, rehabilitering och uppföljning av patienter som gjort självmordsförsök - eller be mötan de av speciella riskgrupper.

- Stöd till anhöriga efterlevande.

- U tvärderingar av suicidpreventiva interventioner.

- Självmordspreventiva projekt inom skolan, till exempel genom att utbilda lärare.

- Kvalificerade bakgrundsanalyser och planer för fortsatt forskning.

Internationell forskarkurs: T he scientific evaluation of suicide preventive interventions

Sedan 2001 organiserar N A SP varje år en internationell forskarkurs med globalt perspektiv på psykisk ohälsa och självmord. Kursen, som pågår i en vecka, vänder sig till doktorander och andra forskare inom suicidologi och suicidprevention. 
Kursens huvudfokus är vetenskaplig utvärdering av självmordspreventiva befolknings- och individinriktade program eller interventioner. Föreläsarna tillhör de främsta internationella forskarna inom suicidologin.

En viktig del av kursen, som varje år lockar 20-25 deltagare från hela världen, är att ge deltagarna tillfälle att ventilera sina planerade eller pågåen de projekt med erfarna forskare.

\section{Kärleken är den bästa kicken}

"Kärleken är den bästa kicken" är namnet på en dokumentärfilm som producerats av N A SP tillsammans med filmaren $G$ öran Setterberg. Filmen beskriver fyra unga vuxna, som överlevt ett självmordsförsök i tonåren och som - var och en med utgångspunkt från sin personlighet och sina sociala omständigheter - kämpar med att återerövra en konstruktiv orientering och en lust att leva.

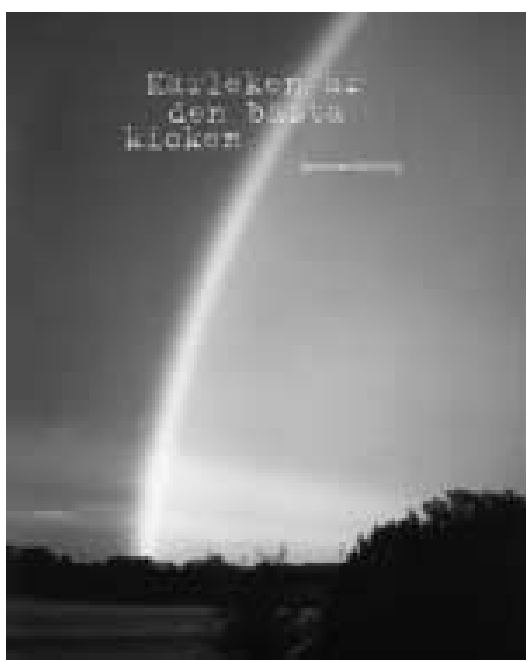

T vå gånger per år anordnar N A SP en tvådagarsutbildning som i första hand vänder sig till lärare och annan skol personal, som sedan kommer att visa filmen på sina skolor. Syftet är att träna vuxna handledare till att med filmen som katalysator leda diskussioner med unga människor om deras frågor om livet och döden. Därmed minskas risken för att ungdomarna ensamma bär sådana frågor inom sig och i värsta fall överväldigas av dem.

De framtida filmvisarna och diskussionsledarna ges i kursen en orientering om utvecklingspsykologiska perspektiv på självmordstankar och -handlingar, om aktuell forskning kring suicidprevention samt i samtalsmetodik med unga.
$M$ agisterutbildning i suicidprevention

Karolinska Institutet har godkänt en magisterutbildning i suicidprevention, som N A SP skall ordna vid Institutionen för folkhälsovetenskap 2005-2006.

Kursen omfattar 40 poäng (två terminers heltidsstudier, motsvarande 60 ECTSpoäng). Den vänder sig till läkare, psykologer, samhällsvetare och andra forskare med ett intresse för suicidprevention.

Kursinnehållet har i jämförelse med Suicidprevention - teori och praktik en större tonvikt på befolkningsinriktad prevention. D elkurser i grundläggande epidemiologisk och folkhälsovetenskaplig metodik ingår i kursen.

Följande huvudmoment ingår i kursen:

(1) introduktion till folkhälsovetenskap;

(2) vetenskaplig metod och principer för uppsatsskrivning;

(3) stress-sårbarhet, den suicidala processen;

(4) befolkningsinriktad prevention, speciella metodfrågor;

(5) självmord i sårbara befolkningsgrupper;

(6) individinriktad prevention, en orientering;

(7) suicidprevention bland barn och ungdomar;

(8) uppsats motsvarande 10 poäng eller 15 ECT S-poäng.

\section{Ö vriga utbildningsinsatser}

Centrets medarbetare medverkar varje år som föreläsare och seminarielärare i läkarutbildningen vid Karolinska Institutet och kurser vid Statens institut för psykosocial medicin (IPM) och Institutionen för folkhälsovetenskap samt som handledare för doktorandprojekt och examensuppsatser inom Karolinska Institutet och Stockholms universitet. M edarbetarna föreläser också regel bundet i kliniska verksamheter och utbildningar utanför N A SP:s egen verksamhet inom området psykisk hälsovård och självmordsprevention.

\section{Referens}

Ramberg, I.-L. (2003). Promoting suicide prevention: A $\mathrm{n}$ evaluation of a programme for training trainers in psychiatric clinical work. Doktorsavhandling. Institutionen för folkhälsovetenskap, Karolinska Institutet, Stockholm.

\section{Magisterutbildning vid Karolinska Institutet och NASP 2005-2006}

En magisterutbildning i suicidprevention kommer att anordnas av Institutionen för folkhälsovetenskap vid Karolinska Institutet och N A SP, det svenska nationella och Stockholms läns landstings center för suicidforskning och prevention av psykisk ohälsa, med start höstterminen 2005.

\section{Kursens mål}

Kursen syftar till att (a) ge kunskaper om biologiska, sociala och psykologiska sårbarhetsfaktorer som i interaktion med yttre påfrestningar ger upphov till psykisk ohälsa och dess yttersta konsekvens, suicid; (b) ge studenterna färdigheter i att vetenskapligt utvärdera och rapportera suicidpreventiva interventioner.

\section{Omfattning}

Ett års heltidsstudier, 40 p (motsvarande 60 ECT S-poäng). I dessa poäng ingår ett uppsatsarbete om 10 poäng (15 ECTS).

\section{Förkunskapskrav}

A vlagd examen om minst 120 poäng (180 ECTS) eller motsvarande utländsk examen.

\section{Ansökan}

A nsökningar kommer att tas emot via internet av Karolinska Institutet, antagningsgruppen för fristående kurser under våren 2005.

\section{Sista anmälningsdag: 15 april 2005.}

För exakt information, bevaka Karolinska Institutets och N A SP:S hemsidor under början av året: http://ki.se/education respektive www.ki.se/suicide

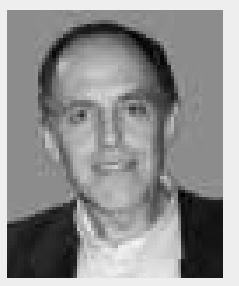

D avid Titelman är fil dr i psykologi och psykoanalytiker. A rbetar vid N A SP i Stockholm som forskare och utbildningsansvarig. 